\title{
Advanced ovulation in gilts by the intrauterine application of a low molecular mass pronase-sensitive fraction of boar seminal plasma
}

\author{
D. Waberski ${ }^{1}$ H. Südhoff ${ }^{1}$, T. Hahn ${ }^{1}$, P. W. Jungblut ${ }^{2}$, E. Kallweit ${ }^{3}$, \\ J. J. Calvete ${ }^{1}$, M. Ensslin ${ }^{1}$, H-O. Hoppen ${ }^{4}$, N. Wintergalen ${ }^{5}$, \\ K. F. Weitze ${ }^{1}$ and E. Töpfer-Petersen ${ }^{1}$ \\ ${ }^{1}$ Institute for Reproductive Medicine, Veterinary School of Hannover, Bünteweg 15, D-30559 Hannover, \\ Germany: ${ }^{2}$ Max-Planck-Institute for Experimental Endocrinology, Feodor-Lynen-Str. 7, \\ D-30625 Hannover, Germany; ${ }^{3}$ Institute of Animal Husbandry and Behaviour, FAL Mariensee, \\ D-31535 Neustadt a. Rbg., Germany; ${ }^{4}$ Department of Endocrinology, Institute for Chemistry, Veterinary \\ School of Hannover, Bünteweg 15, D-30559 Hannover, Germany; and ' University Women's Hospital, \\ Department Prof. Schlegel, Domagkstr. 11, D-48161 Münster, Germany
}

\begin{abstract}
The shortening of the time interval between the onset of oestrus and ovulation in sows by the transcervical administration of seminal plasma was investigated in 23 German Landrace gilts, using the technique of single horn infusions (Mariensee model) in combination with the transcutaneous sonographic monitoring of ovaries. Preparative surgery comprised the detachment of the left uterine horn from the corpus, leaving the caudal end open to the peritoneal cavity but sealing the corpus wound. The left ovary was loosely tied to the ventral abdominal wall for better sonographic distinction. The animals were used in two to four consecutive cycles. After detection of oestrus by the teaser boar, the patent (right) horns were filled by transcervical infusion of $100 \mathrm{ml}$ of a variety of test solutions. Ovulation was probed by transcutaneous sonography at intervals of $4 \mathrm{~h}$ thereafter. Native seminal plasma provoked ovulation in the ipsilateral ovary of the treated horn $10.7 \mathrm{~h}$ earlier than in the contralateral ovary. This effect was reduced to $7.3 \mathrm{~h}$ after charcoal treatment of seminal plasma; addition of $10 \mu \mathrm{g}$ oestradiol restored the effect in full, while $10 \mu \mathrm{g}$ of oestradiol in PBS shortened the time interval to only $3.3 \mathrm{~h}$ versus the control ovary. Little effect was seen with oestrone sulfate, none with prostaglandins in PBS or with PBS alone. The preliminary characterization of the nonsteroidal component of seminal plasma advancing ipsilateral ovulation after transcervical infusion suggests a proteinaceous nature. The activity resides in the $1-10 \mathrm{kDa}$ fraction separated by ultrafiltration and is lost after treatment with pronase.
\end{abstract}

\section{Introduction}

The intervals between the onsets of oestrus and ovulation in sows vary widely (Weitze et al., 1994). Maximal fertilization rates require an interval of no more than $12 \mathrm{~h}$ between insemination and ovulation (Waberski et al., 1994). It is well known that boars exert a stimulative effect on the onset and intensity of oestrous behaviour in sows (Signoret, 1970; Hughes et al., 1990). Natural mating shortens the interval between the onset of oestrus and ovulation (Signoret et al., 1972). This phenomenon has been explained as a stimulatory effect of copulation on the hypothalamus-hypophyseal axis via receptors found in the vagina and the cervix with subsequent enhancement of LH concentrations in blood plasma (Ziecik et al., 1981). Claus (1989) and Weiler and Claus (1991) suggested that the oestrogens present in boar semen in

Revised manuscript received 4 September 1995. amounts of up to $11.5 \mu \mathrm{g}$ are the specific trigger for release of prostaglandins from the endometrium; prostaglandins reach the ovary via a capillary network and increase the prostaglandin concentration in the follicular fluid. In addition, the seminal oestrogens could act systemically by provoking an LH surge (Claus 1989). With the establishment of transcutaneous sonography as a non-invasive and stress-free tool for the detection of ovulation in unanaesthetized pigs (Weitze et al., 1989), the effect of seminal plasma in advancing ovulation has been ascertained. Transcervical infusions of oestrogen in saline also have some effect, but this is markedly surpassed by seminal plasma containing comparable concentrations of oestrogens (Weitze et al., 1990). In the present study, we investigated evidence for a local effect of seminal plasma constituents other than oestrogens. The Mariensee model (Jungblut et al., 1991), which allows for a clear distinction between local and systemic effects, was used in combination with the transcutaneous sonographic monitoring of ipsi- and contralateral ovaries. 


\section{Materials and Methods}

Animals and surgery

Twenty-three German landrace gitts with an average body mass of $95 \mathrm{~kg}$ were surgically prepared according to the Mariensee model (Jungblut et al., 1991). Surgery was carried out at the Institute for Animal Husbandry and Behaviour FAL, Mariensee, under general anaesthesia using Stresnil ${ }^{\mathbb{R}}$ (Janssen GmbH, Neuss) and Nembutal ${ }^{\text {1: }}$ (WDT, Hannover). A schematic design of the model is given (Fig. I). After midventral incision and proposition of the corpus uteri and the adjacent part of the cervix, a section $(7 \mathrm{~cm} \times 2 \mathrm{~cm})$ of the parametrium at the caudal end of the left horn and the cervix was coagulated at about $150^{\circ} \mathrm{C}$ by 'ironing' with a custom-made 'foot' attached to a thermostated soldering rod (set to $350^{\circ} \mathrm{C}$ ) against a Teflon 'board'. The serosa of the left horn about $5 \mathrm{~cm}$ above the corpus was rounded with the iron, the left horn-cervix junction was ligated with catgut and a section (about $2 \mathrm{~cm}$ ) of the left horn between the ligation and ironed circle was excised. The ligated part of the horn left at the corpus was thoroughly cauterized at the cutting edge and in the lumen to ensure permanent sealing after the discharge of decay. All traces of blood shed during the operation were carefully removed to avoid adhesions. For easier sonographic distinction, the mesovarium of the left ovary was attached to the abdominal wall next to the incision using a synthetic yarn (Synthofil ${ }^{\mathbf{B}}$ : Braun, Melsungen). Animals were allowed to recover from surgery in individual pens for 14 days and were then transported to the Hannover Veterinary School. They were housed in groups of two or three with olfactory and visual contact with the boar. Oestrus was detected by contact twice a day with the teaser boar $(08: 00 \mathrm{~h}, 20: 00 \mathrm{~h})$. The gilts became quickly acquainted with the personnel and got used to the examination stand and sonographic equipment.

\section{Transcervical infusions}

Transcervical infusions of 14 different solutions into the patent horns were performed by insemination catheters immediately after tolerance to mounting by the boar. Aliquots of $100 \mathrm{ml}$ were applied, and refluxes were collected for $5 \mathrm{~min}$ after completion of the infusion. The animals were used in two to four consecutive oestrous periods, beginning with the second oestrus after stalling: five gilts were used in four cycles, nine gilts in three cycles, and nine gilts in two cycles. Within each treatment group different gilts were used.

\section{Assessment of the interval between the onsets of oestrus and ovulation}

The beginning of oestrus was set at the middle of the time interval between the last rejection of mounting and the first tolerance. During oestrus, the ovaries were examined sonographically every $4 \mathrm{~h}$ (04:00, 08:00, 12:00, 16:00, 20:00, 24:00 h) to determine the time of ovulation. Transcutaneous sonography was performed using a $5 \mathrm{MHz}$ sector scanner (Sonoline SX ${ }^{\mathrm{R}}$ : Siemens, Erlangen), as described by Weitze et al. (1989). Ovulation was assumed to have occurred at the middle of the time interval between the last detection of

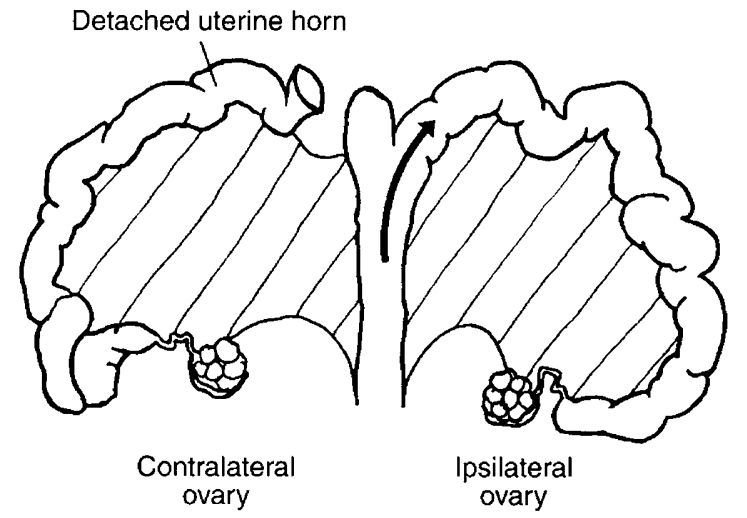

Fig. 1. Schematic design of the Mariensee model. The arrow indicates the flow of an inseminated solution.

follicles and their subsequent disappearance. Fewer follicles than were seen in the previous examination followed by complete disappearance of follicles at the next examination was taken as a sign of ongoing ovulation. In this case, the time at which a reduction in numbers of follicles was registered was taken as the time of ovulation. The criterion for distinguishing between the left and right ovaries was their position relative to the bladder and the sonograph probe. The effect of an infused solution in enhancing ovulation was calculated from the mean difference between the times of ovulation of the ipsilateral (treated horn) and the contralateral (control) ovaries in six gilts. Simultaneous ovulations at both ovaries in at least three gilts were taken as proof of the ineffectiveness of an infusate to advance ovulation by a local mechanism. In this case, it was assured that in at least two of these three gilts ovulation had been advanced after the infusion of seminal plasma, or an active component thereof, so that an animal specific cause (e.g. postsurgical adhesion) for the negative result could be eliminated.

\section{Solutions infused}

Seminal plasma. Semen samples from four fertile boars were collected over 4 months. They were centrifuged at $3000 \mathrm{~g}$ for $20 \mathrm{~min}$ and the cell-free plasma was stored frozen at $-20^{\circ} \mathrm{C}$. Plasma pools were prepared by thawing the frozen samples and mixing them when fully thawed.

Charcoal treatment of seminal plasma. Activated charcoal powder ( $5 \mathrm{~g}$; Merck, Darmstadt) was added to 11 of thawed seminal plasma; the suspension was stirred for $1 \mathrm{~h}$ at $4^{\circ} \mathrm{C}$ and then centrifuged at $3000 \mathrm{~g}$ for $20 \mathrm{~min}$. The supernatant was again treated with charcoal for $24 \mathrm{~h}$, and the suspension cleared by centrifugation and filtration through fluted filters. Aliquots of $100 \mathrm{ml}$ were frozen and stored at $-20^{\circ} \mathrm{C}$ until use.

Spiking of charcoal-treated seminal plasma with oestradiol. Immediately before use, $10 \mu \mathrm{g}$ oestradiol (Sigma, St Louis, MO) dissolved in $0.1 \mathrm{ml} 96 \%(\mathrm{v} / \mathrm{v})$ ethanol was added to $100 \mathrm{ml}$ of charcoal-treated seminal plasma.

Oestradiol $(10 \mu \mathrm{g})$ was dissolved in $0.1 \mathrm{ml} 96 \%(\mathrm{v} / \mathrm{v})$ ethanol and added to $100 \mathrm{ml}$ PBS containing $3 \%(\mathrm{w} / \mathrm{v}) \mathrm{BSA}$. 
Oestrone sulfate. Since most of the oestrogens found in seminal plasma are conjugated, the effect of $7.8 \mu \mathrm{g}$ oestrone sulfate (Sigma) in $100 \mathrm{ml}$ PBS containing 3\% (w/v) BSA was tested.

Prostaglandins. Prostaglandin $\mathrm{F}_{2 \alpha}\left(\mathrm{PGF}_{2 \alpha}\right)(250 \mu \mathrm{g}$ Dinoprost; Dinolytic ${ }^{(1)}$ : Upjohn Heppenheim) or PGF $_{2}(250 \mu \mathrm{g}$ Dinoproston; Minprostin ${ }^{\circledR}$ : Upjohn Heppenheim) was dissolved in $100 \mathrm{ml}$ PBS.

Fractionation of charcoal-treated seminal plasma by gel-exclusion chromatography and ultrafiltration. The plasma was adjusted to $\mathrm{pH} 4.5$ and passed through two columns $(5 \mathrm{~cm} \times 100 \mathrm{~cm})$ of Sephadex G-50 superfine (Pharmacia-LKB, Uppsala) set in series, equilibrated with 1 mol sodium formiate $\mathrm{I}^{-1}, \mathrm{pH} 4.5$. Two macromolecular peaks were obtained: peak I contained $>60 \mathrm{kDa}$ proteins, peak 2 consisted of non-aggregated $16-20 \mathrm{kDa}$ spermadhesin proteins. Both peaks were neutralized, concentrated by ultrafiltration and adjusted to the starting volume of $100 \mathrm{ml}$. For fractionation by ultrafiltration, $100 \mathrm{ml}$ portions of seminal plasma were first passed through PM 10 membranes (Amicon $\mathrm{GmbH}$, Witten). The filtrate was either tested as such or passed through YM I membranes, and the filtrates and retentates recovered. All fractions were analysed by SDS-PAGE and reconstituted to the original volume by addition of PBS before infusion.

Digestion with pronase. The $1-10 \mathrm{kDa}$ fractions of the ultrafiltration experiment were digested with pronase by adding $0.1 \mathrm{mg}$ enzyme to $10 \mathrm{ml}$ of concentrate and incubating the mixture for $2 \mathrm{~h}$ at $38^{\circ} \mathrm{C}$. The enzyme was recovered by passage through Centricon ${ }^{\mathrm{R}}-30$ (Amicon $\mathrm{GmbH}$ ) and the filtrate was adjusted to $100 \mathrm{ml}$ by addition of PBS.

\section{Hormone assays}

Unconjugated oestrogens. Total unconjugated oestrogens were extracted from seminal plasma aliquots $(5-50 \mu \mathrm{I})$ with ethyl acetate and determined by radioimmunoassay. The antiserum directed against oestrone-17-CMO-BSA (G. Emons and R. Knupen, Med. Univ. Lübeck, Germany) crossreacted $100 \%$ with oestradiol, $19.1 \%$ with $17 \alpha$-oestradiol and $<0.1 \%$ with testosterone, androstendione, progesterone and cortisol. Dried sample extracts were resuspended in $100 \mu \mathrm{l}$ assay buffer $\left(0.01 \mathrm{~mol} \mathrm{NaH}_{2} \mathrm{PO}_{4} \mathrm{l}^{-1}, 0.01 \mathrm{~mol}\right.$ EDTA I ${ }^{-1}$, containing $0.1 \%$ $(\mathrm{w} / \mathrm{v})$ lysozyme, $\mathrm{pH} 7.2) .\left[2,4,6,7_{-}{ }^{3} \mathrm{H}\right]$ oestradiol (Amersham, Buchler) was added as tracer at 12000 c.p.m. in $100 \mu l$ assay buffer, and the mixture was incubated with $100 \mu \mathrm{l}$ of a 1:120 000 antiserum dilution at $4^{\circ} \mathrm{C}$ for $18 \mathrm{~h}$. Free and bound steroids were separated by dextran-coated charcoal (Separex ${ }^{\text {(i) }}$ : S. Klinger, St Albans; $2 \mathrm{mg}$ per $0.5 \mathrm{ml}$ assay buffer), and the bound fraction was mixed with $1 \mathrm{ml}$ scintillation fluid (Ready Organic, Beckmann Instruments, Fullerthon, $C A$ ) and radioactivity was measured in a $\beta$ counter. The minimal detectable concentration was $2 \mathrm{pg}$; zero binding was $37 \%$; and intra- and interassay coefficients of variation were $8.3 \%$ and $12.4 \%$, respectively.

Conjugated oestrogens. Oestrogen sulfates and glucuronides were cleaved by enzyme hydrolysis and the steroids were extracted with ethyl acetate and estimated by radioimmunoassay. Seminal plasma aliquots $(5-50 \mu \mathrm{l})$ were diluted with $300 \mu \mathrm{CH}_{3} \mathrm{COONa}\left(0.05 \mathrm{~mol} \mathrm{l}^{-1}, \mathrm{pH} 4.5\right)$ and incubated with $\beta$-glucuronidase/arylsulfatase ( $10 \mu \mathrm{l}$, Helix pomatia, $5.5 \mathrm{U}$ $\beta$-glucuronidase $\mathrm{ml}^{-1}$ and $2.6 \mathrm{U}$ arylsulfatase $\mathrm{ml}^{-1}$ (Boehringer, Mannheim) at $37^{\circ} \mathrm{C}$ for $15 \mathrm{~h}$. After cooling, the mixture was extracted with ethyl acetate $(3 \mathrm{ml})$ and the dried extract was subjected to the total oestrogen radioimmunoassay as described above. Recovery of oestradiol-3-glucuronide (R. Knuppen, Med. Univ. Lübeck) or oestrone sulfate (Sigma, Deisenhofen) was $75 \%$ and $82 \%$, respectively.

Oestradiol. Concentrations of oestradiol were determined by radioimmunoassay as described by Behrens et al. (1993). The minimal detectable concentration was $2 \mathrm{pg} \mathrm{ml}^{-1}$. Intraand interassay coefficients of variation were 9.55 and $11.8 \%$, respectively.

Prostaglandin. Concentrations of $\mathrm{PGF}_{2 \alpha}$ and $\mathrm{PGE}_{2}$ in frozen-thawed seminal plasma were measured by fluoroimmunoassay after extraction of $500 \mu \mathrm{l}$ aliquots with $8 \mathrm{ml}$ ethyl acetate at $\mathrm{pH}$ 3.5. The organic phase was dried with a gentle stream of nitrogen gas, and samples were further treated as described by Lüke and Schlegel (1990). The detection limit for $\mathrm{PGF}_{2 \alpha}$ was $2.2 \mathrm{pg}$, and for $\mathrm{PGE}_{2} 1.3 \mathrm{pg}$ per microtitre well. The average intra-assay coefficient of variation for both types of prostaglandins was below $10 \%$. The interassay coefficient of variation for $\mathrm{PGF}_{2 \alpha}$ was $13.4 \%$, and for $\mathrm{PGE}_{2} 13.0 \%$.

\section{Statistical analyses}

Statistical analyses were made using SAS (SAS/STAT, 1989). The effects of treatment and each of the following variables: number of cycle, volume of reflux and duration of oestrus were tested by two-way analysis of variance. Since none of the variables showed a statistically significant influence on the time difference between ipsi- and contralateral ovulations, a oneway analysis of variance with the factor treatment neglecting the covariables was used to test for differences between the infused solutions. The pairwise comparisons between any two of the means were made using the Ryan-Einot-GabrielWelsch multiple range test (SAS/STAT, 1989).

In the groups showing the highest effects and the highest ranges (seminal plasma and charcoal-treated seminal plasma $+10 \mu \mathrm{g}$ oestradiol), the dependence of the time differences between ipsilateral and contralateral ovulations on the interval between the onset of oestrus and ovulation in contralateral ovaries was shown using the linear regression coefficient.

\section{Results}

Hormone contents of native and charcoal-treated seminal plasma

From the total amount of $9.2 \mathrm{ng}$ oestrogens $\mathrm{ml}^{-1}$ measured in the native seminal plasma, $8.6 \mathrm{ng} \mathrm{ml}^{-1}$ were conjugated. Charcoal treatment reduced the oestrogen content by $98.7 \%$ (Table 1). The concentration of oestradiol in charcoal-treated seminal plasma was below the detection limit. Neither $\mathrm{PGF}_{2 \alpha}$ nor $\mathrm{PGE}_{2}$ were found in frozen-thawed seminal plasma. 
Table 1. Concentrations of oestrogens and prostaglandins in native and charcoal-treated seminal plasma of boars

\begin{tabular}{lcc}
\hline & \multicolumn{2}{c}{ Seminal plasma } \\
\cline { 2 - 3 } Constituents $\left(\mathrm{pg} \mathrm{ml}^{-1}\right)$ & Native & Charcoal-treated \\
\hline & & \\
Total oestrogens & 9200 & 120 \\
Unconjugated oestrogens & 600 & 5 \\
Oestradiol & 135 & nd \\
Prostaglandin $\mathrm{F}_{2 u}$ & nd & nd \\
Prostaglandin $\mathrm{E}_{2}$ & nd & nd \\
\hline
\end{tabular}

nd: not detectable.

\section{Effects of infusates on the time interval between the onsets of oestrus and ovulation}

In gilts infused with seminal plasma, the intervals between the onset of oestrus and ovulation were, on average, $10.7 \mathrm{~h}$ $(8-14 \mathrm{~h})$ shorter in the ipsilateral than in the contralateral (control) ovaries (Table 2). The duration of oestrus, the number of cycles and the volumes of refluxes, ranging from 0 to $52 \mathrm{ml}$, had no influence on the results. Treatment of seminal plasma with activated charcoal reduced the difference between the treated and untreated side by $3.4 \mathrm{~h}$. This reduction was apparently equalized by adding $10 \mu \mathrm{g}$ oestradiol to the charcoal-treated seminal plasma. The mixture advanced ovulation in the ipsilateral ovaries by $10 \mathrm{~h}$, compared with the control. In this group, and in the seminal plasma group, the differences between ipsi- and contralateral ovulations depended $\left(r^{2}=0.43, P<0.05\right)$ on the interval from the onset of oestrus to ovulation in the contralateral (control) ovary (Fig. 2). Oestradiol $(10 \mu \mathrm{g})$ in PBS resulted in ovulations occurring $3.3 \mathrm{~h}$ earlier in the experimental, right-side ovaries. The same figure was obtained with $7.8 \mu \mathrm{g}$ oestrone sulfate in PBS. Treatments with prostaglandins and with fractions of the separation experiments with molecular masses $<I$ and $>10 \mathrm{kDa}$ were ineffective. Advanced ovulations were seen with the PM 10 filtrate of charcoal-treated seminal plasma ( $6.8 \mathrm{~h}$ on average) and its YM I retentate ( $5.3 \mathrm{~h}$ on average). The earlier ovulation of $6.8 \mathrm{~h}$ is not different from the $7.3 \mathrm{~h}$ observed with charcoaltreated seminal plasma. The interval of $5.3 \mathrm{~h}$ seen with the $1-10 \mathrm{kDa}$ YM I retentate was significantly different from the $7.3 \mathrm{~h}$ value, but not from the $6.8 \mathrm{~h}$ of the PM 10 filtrate. Treatment of the $1-10 \mathrm{kDa} Y M \quad 1$ retentate with pronase resulted in a complete loss of the effect.

\section{Discussion}

We previously reported that the transcervical infusion of boar seminal plasma shortens the interval between the onset of oestrus and ovulation by about $14 \mathrm{~h}$ compared with untreated controls (Weitze et al., 1990). The high variations in oestrous behaviour and time of ovulations in sow herds (Weitze et al., 1994) required the study of a large number of cycles to obtain significant data. The Mariensee model used in this study requires fewer animals, since the times of ovulations at the patent sides of the uterus can be compared with those in the control ovaries of the detached uterine horns. The model allows for the distinction between local and systemic effects. The differences observed identify the effects seen as local phenomena. It was demonstrated that a transcervical infusion of seminal plasma in one uterine horn advanced ovulation on the ipsilateral ovary for $10.7 \mathrm{~h}$, on average, compared with the contralateral ovary. The effect is more pronounced in gilts that show long intervals between the onset of oestrus and ovulation on the control ovary, compared with gilts with earlier contralateral ovulations. Previous data from 303 spontaneously ovulating gilts, collected during 3 years in the Institute of the Hannover Veterinary School, revealed a mean interval between the onset of oestrus and ovulation of $39.5 \mathrm{~h}$, ranging from 24 to $64 \mathrm{~h}$ (K. F. Weitze and D. Waberski, unpublished). Since in the present study, the mean interval from the onset of oestrus to ovulation of the control ovaries in gilts infused with seminal plasma was $45.3 \mathrm{~h}$, ranging from 40 to $56 \mathrm{~h}$, it can be concluded that systemic effects do not contribute to the ovulation-advancing effect. Steroid depletion of seminal plasma reduced the effect significantly, and this could be compensated for by adding oestradiol to charcoal-treated seminal plasma. The difference of $3.4 \mathrm{~h}$ between steroid-depleted and native seminal plasma corresponds to the effect of oestrogens in PBS, thereby indicating an additive effect of oestrogens and a non-steroidal component of seminal plasma. The ineffectiveness of some infusates also discounts the possibility of distension reflexes. The contribution of oestrogens in seminal plasma to earlier ovulations appears less pronounced than that of small proteinaceous constituents. Since oestrogens in seminal plasma occur mainly in a conjugated form and a receptor independent local effect of oestrogens in the uteri of pigs has been described (Jungblut et al., 1979, 1989), oestrone sulfate was tested in the present study and was found to be as effective as oestradiol. Claus (1989) suggested that the oestrogens in seminal plasma provoke the synthesis of prostaglandins in the endometrium. They would travel from there via the parametrial/mesovarial capillary bed to the ovary, increase the prostaglandin concentrations in the follicular fluid and trigger follicle rupture. However, infusions of prostaglandins in quantities that caused a substantial rise in concentration in the uterine vein comparable with that measured by Claus (1989) after the intrauterine application of oestrogens (Okrasa et al., 1985) did not advance follicle rupture in the ipsilateral ovary. The observation of Kotwica (1980) that prostaglandins infused into the anterior uterine vein on day 14 of the oestrous cycle in pigs also caused regressive changes in the contralateral ovary indicates the presence of effective pathways for prostaglandins from one uterine horn to the opposite ovary. This is a possible argument against the mechanism of seminal plasma action suggested by Claus (1989) since, in the present study, the local, unilateral effect of seminal fluid upon the time of ovulation in gilts was clearly established.

Although the concentrations of FSH and LH in the peripheral blood plasma were not measured in the present study, the different timings of ovulation between the treated and the control sides rule out the possibility of increased plasma concentrations as the ovulation elicitor. The conclusions drawn from experiments with camels in which GnRH-like factors present in seminal plasma were suspected of acting on the pituitary (Zhao et al., 1990, 1992) indicate a different 


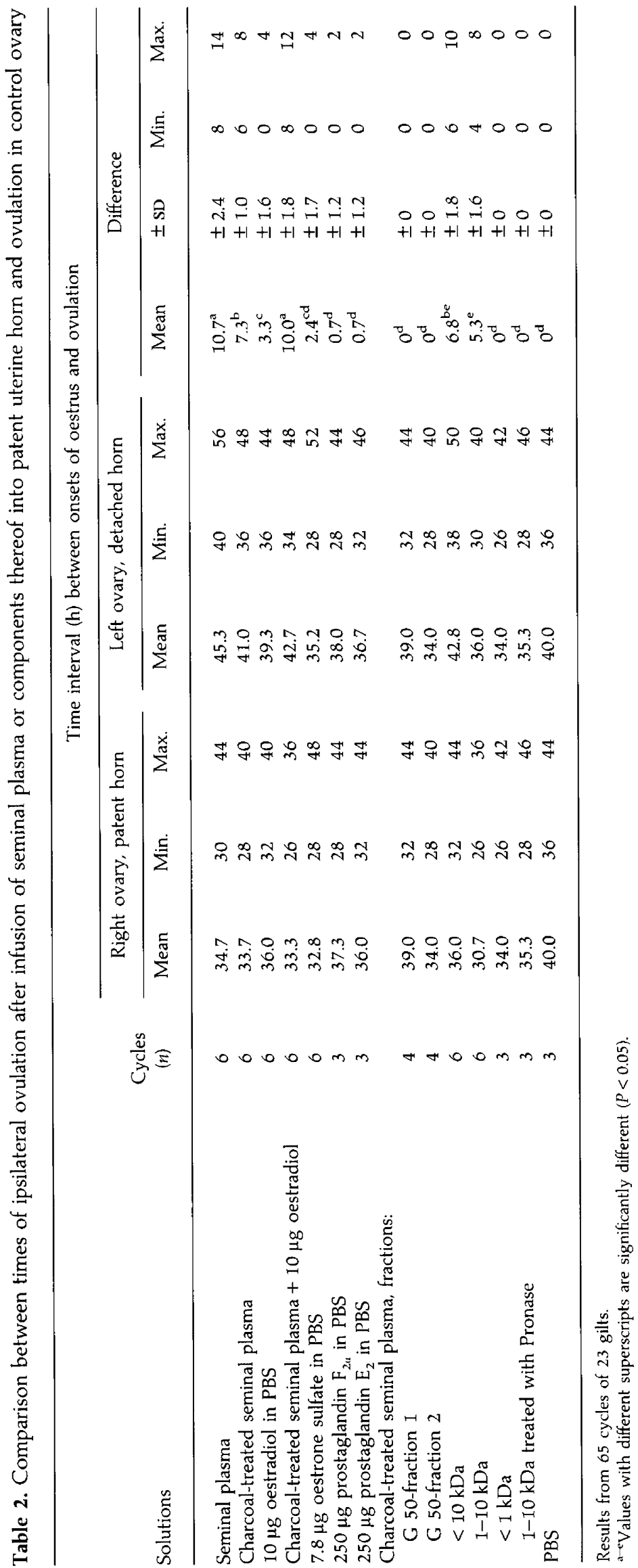




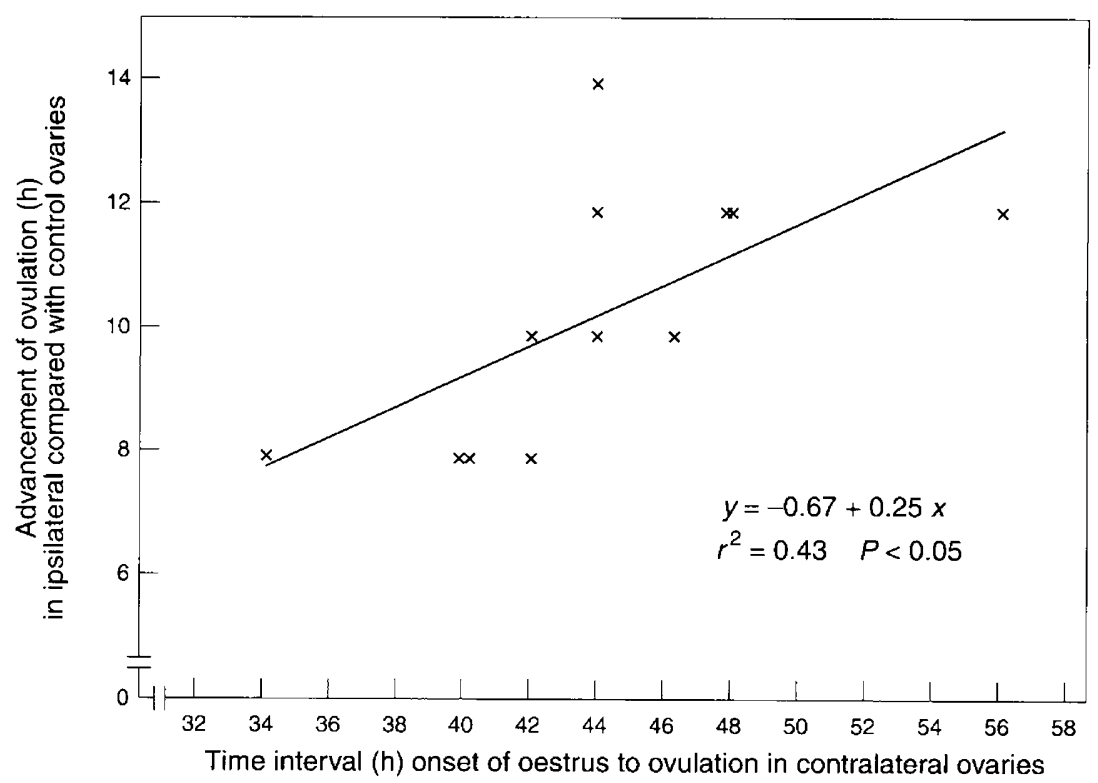

Fig. 2. Relation of the time interval between the onset of oestrus and ovulation in contralateral (control horn) ovaries and the ovulation advancing effect on ipsilateral (treatment horn) ovaries after transcervical infusion of seminal plasma or charcoal treated seminal plasma + oestradiol $(n=12$ gilts).

mechanism of seminal plasma in this species with copulationinduced ovulation. The key role of the $1-10 \mathrm{kDa}$ fraction of seminal plasma in eliciting ovulation seems to be without dispute. The isolation of the active factor(s), therefore, is of utmost importance in identifying the primary site of action and elucidating the molecular mechanisms of the subsequent events.

This study was supported by the Association of German Pig Producers (ZDS, Bonn). The authors thank J. A. G. Soares and $M$. Beyerbach for their help and the Upjohn Company, Heppenheim, for providing the prostaglandins.

\section{References}

Behrens C, Aurich JE, Klug E, Naumann H and Hoppen H-O (1993) Inhibition of gonadotrophin release in mares during the luteal phase of the oestrous cycle by endogenous opioids Journal of Reproduction and Fertility 98 509-514

Claus R (1989) Oestrogens of the boar: effects on male and female reproductive functions. In Reproductive Biology and Medicine pp 136-147 Eds AF Holstein, KD Voigt and D Graesslin. Diesbach Verlag, Germany

Hughes PE, Pearce GP and Patterson AM (1990) Mechanisms mediating the stimulatory effects of the boar on gilt reproduction Journal of Reproduction and Fertility Supplement 40 323-341

Jungblut PW, Hughes A, Gaues J, Kallweit E, Maschler I, Parl F, Sierralta W, Szendro P and Wagner RK (1979) Mechanisms involved in the regulation of steroid receptor levels Journal of Steroid Biochemistry 11 273-278

Jungblut PW, Sierralta WD, Szendro PI, Gaues J, Wiechert R, Bohlmann R and Bittler D (1989) Receptor deprivation with unimpaired edema formation in porcine uteri by 'dissociated estrogens' Acta Endocrinologica 120 Supplement 1 160-161

Jungblut PW, Sierralta WD, Henning, M and Kallweit E (1991) Die transzervikale Injektion in das Uteruslumen von kastrierten Schweinen als zell- und organbiologische Versuchsanordnung. Das Mariensee Modell Journal of Experimental Animal Science 34 229-235

Kotwica J (1980) Mechanism of prostaglandin $\mathrm{F}_{24}$ penetration from the horn of the uterus to the ovaries in pigs Journal of Reproduction and Fertility 59 237-241
Lüke FJ and Schlegel W (1990) A time-resolved fluoroimmunoassay for the determination of prostaglandin $\mathrm{F}_{2 u}$ Clinica Chimica Acta 189257 266

Okrasa SO, Tilton JE and Weigl RM (1985) Utero-ovarian concentrations of prostaglandin $\mathrm{E}_{2}\left(\mathrm{PGE}_{2}\right)$ and prostaglandin $\mathrm{F}_{2 \mathrm{a}}\left(\mathrm{PGF}_{2 \mathrm{u}}\right)$ following $\mathrm{PGE}_{2}$ intrauterine infusions Prostaglandins 30 851-855

SASISTAT (1989) User's Guide (Vol. 1 and 2) SAS Institute Inc, Cary, NC

Signoret JP (1970) Reproductive behaviour in pigs Journal of Reproduction and Fertility Supplement 11 105-117

Signoret JP, du Mesnil du Buisson F and Mauléon P (1972) Effect of mating on the onset and duration of ovulation in the sow Journal of Reproduction and Fertility 31 327-330

Waberski D, Weitze KF, Gleumes T, Schwarz M, Willmen T and Petzoldt R (1994) Effect of time of insemination relative to ovulation on fertility with liquid and frozen boar semen Theriogenology 42 831-840

Weiler U and Claus R (1991) Endocrine aspects of testicular function, especially hormones in the seminal plasma, and their fate in the female reproductive tract: testicular steroids and their relevance for male and female reproductive functions Reproduction in Domestic Animals Supplement 1 $41-61$

Weitze KF, Habeck O, Willmen T and Rath D (1989) Detection of ovulation in the sow using transcutaneous sonography Zuchthygiene 24 40-42

Weitze KF, Lotz JH, Everwand A, Willmen T and Waberski D (1990) Interaction between inseminate, uterine and ovarial function in the sow. II: Investigations into the influencing of ovulation by the use of sperm-free media Reproduction in Domestic Animals 25 197-204

Weitze KF, Wagner-Rietschel H, Waberski D, Richter L and Krieter J (1994) The onset of heat after weaning, heat duration, and ovulation as major factors in AI timing in sows Reproduction in Domestic Animals 29 433-443

Zhao XX, Pan GW, Huang YM, Gao YH and Chen BX (1990) Studies on the ovulation-inducing factor in the seminal plasma of the bactrian camel. In: Is it Possible to Improve the Reproductive Performance of the Camel? Proceedings UCDEC Workshop, Paris 1990

Zhao XX, Huang YM and Chen BX (1992) Biological activity of gonadotrophinreleasing hormone-like factors in the seminal plasma of the Bactrian camel. In: Proceedings of the First International Camel Conference pp 163-168 Eds WR Allen, AJ Higgins, IG Mayhew, DH Snow and JF Wade. R\&W Publications, Newmarket

Ziecik A, Tilton JE and Williams GL (1981) Effect of mating on the luteinizing hormone surge in the pig Journal of Animal Science 53 434-438 